University of Nebraska - Lincoln

DigitalCommons@University of Nebraska - Lincoln

\title{
Response Of Adult Mosquitoes To Light-Emitting Diodes Placed In Resting Boxes And In The Field
}

\author{
Michael T. Bentley \\ University of Florida \\ Phillip E. Kaufman \\ University of Florida \\ Daniel L. Kline \\ United States Department of Agriculture \\ Jerome A. Hogsette \\ United States Department of Agriculture
}

Follow this and additional works at: https://digitalcommons.unl.edu/usdaarsfacpub

Part of the Agricultural Science Commons

Bentley, Michael T.; Kaufman, Phillip E.; Kline, Daniel L.; and Hogsette, Jerome A., "Response Of Adult Mosquitoes To Light-Emitting Diodes Placed In Resting Boxes And In The Field" (2009). Publications from USDA-ARS / UNL Faculty. 997.

https://digitalcommons.unl.edu/usdaarsfacpub/997

This Article is brought to you for free and open access by the U.S. Department of Agriculture: Agricultural Research Service, Lincoln, Nebraska at DigitalCommons@University of Nebraska - Lincoln. It has been accepted for inclusion in Publications from USDA-ARS / UNL Faculty by an authorized administrator of DigitalCommons@University of Nebraska - Lincoln. 


\title{
RESPONSE OF ADULT MOSQUITOES TO LIGHT-EMITTING DIODES PLACED IN RESTING BOXES AND IN THE FIELD
}

\author{
MICHAEL T. BENTLEY, ${ }^{1}$ PHILLIP E. KAUFMAN, ${ }^{1,3}$ DANIEL L. KLINE, ${ }^{2}$ and JEROME A. HOGSETTE ${ }^{2}$
}

\begin{abstract}
The response of adult mosquitoes to 4 light-emitting diode (LED) wavelengths was evaluated using diode-equipped sticky cards (DESCs) and diode-equipped resting boxes at 2 sites in north central Florida. Wavelengths evaluated were blue $(470 \mathrm{~nm})$, green $(502 \mathrm{~nm})$, red $(660 \mathrm{~nm})$, and infrared (IR) $(860 \mathrm{~nm})$. When trapping with DESCs, 15 mosquito species from 7 genera (Aedes, Anopheles, Coquillettidia, Culex, Mansonia, Psorophora, and Uranotaenia) were captured. Overall, approximately $43.8 \%$ of all mosquitoes were trapped on DESCs fitted with green LEDs. Significantly more females of Aedes infirmatus, Aedes vexans, and Culex nigripalpus were captured on DESCs fitted with blue LEDs compared with red or IR LEDs. DESCs with blue LEDs captured significantly more Culex erraticus females than those with IR LEDs. Using resting boxes, 12 species from 5 genera (Anopheles, Coquillettidia, Culex, Mansonia, and Uranotaenia) were collected. Resting boxes without LEDs captured 1,585 mosquitoes (22.2\% of total). The fewest number of mosquitoes (16.7\%) were collected from boxes affixed with the blue LEDs. Significantly more Anopheles quadrimaculatus females were aspirated from resting boxes fitted with red and IR LEDs than from those with blue or green LEDs, or from the unlit control. Blood-fed mosquitoes were recovered in highest numbers from unlit resting boxes, followed by resting boxes fitted with green, IR, and blue LEDs. Culex erraticus accounted for the majority of blood-fed mosquitoes followed by Coquillettidia perturbans. No blood-fed mosquitoes were recovered from resting boxes fitted with red LEDs.
\end{abstract}

KEY WORDS Attraction, resting box, wavelength, Culicidae, vision

\section{INTRODUCTION}

Since the early 1900 s, the effectiveness of techniques to attract and track the movements of hematophagous insects has continued to improve (Crans 1995). Adequate and reliable population sampling is frequently seen as the most important and most difficult step in ecological studies. Sampling outdoor mosquito populations is often difficult, because of behavioral differences between species and the fact that mosquitoes, in general, are not equally distributed within a habitat (Crans 1995). As a result, a variety of trapping systems have been developed that have been further enhanced with artificial, reflected, or filtered lights with great success (Barr et al. 1963, Ali et al. 1989, Service 1993, Burkett and Butler 2005, Hoel 2005). However, traps produce a bias when used in vector surveillance and population monitoring by primarily selecting nonblood-fed, host-seeking mosquitoes. Collections of resting mosquitoes yield a more accurate representative sample of a mosquito population, recovering not only nonblood-fed, host-seeking individuals, but also males, as well as blood-fed

${ }^{1}$ Entomology and Nematology Department, PO Box 110620, Institute of Food and Agriculture Sciences, University of Florida, Gainesville, FL 32611-0620.

${ }^{2}$ United States Department of Agriculture-Agricultural Research Service, Center for Medical, Agricultural, and Veterinary Entomology, 1600 SW 23rd Drive, Gainesville, FL 32608.

${ }^{3}$ To whom correspondence should be addressed. Phillip E. Kaufman Entomology and Nematology Department PO Box 110620 Gainesville, FL 326110620 . and gravid females (Bradley 1943, Hayes et al. 1958, Loomis and Sherman 1959).

Mosquitoes often rest or seek shelter in protected sites (Crans 1995). The capitalization on this natural phenomenon has allowed researchers to effectively sample mosquitoes during inactive hours using artificial resting boxes (Goodwin 1942). Several laboratory and field studies have been conducted to determine the behavior of adult Diptera in response to visual stimuli, with special attention given to the modification of light wavelength and intensity in Culicidae (Huffaker and Back 1943, Fox 1958, Bidlingmayer 1967, Burkett and Butler 2005). Headlee (1937) first observed the impact of varying light intensities on catch size after noting that increased numbers of mosquitoes were attracted to within a certain proximity of traps. Previous studies have also demonstrated the effects of wavelength variation on field populations of Culex and Psorophora. Higher proportions of Culex nigripalpus Theobald, Culex erraticus Dyar and Knab, Psorophora columbiae Dyar and Knab, and Psorophora ciliata Fabricius were collected with New Jersey light traps modified with incandescent blue lights than with traps modified with yellow, orange, green, red, or white lights (Ali et al. 1989).

Much of what is known today concerning the affinity of Diptera to different light wavelengths can be credited to studies in which scientifically imprecise light sources were used (Brett 1938, Bracken et al. 1962, Bradbury and Bennett 1974, Browne and Bennett 1981, Allan and Stoffolano 1986). The recent development of super-bright 
light-emitting diodes (LEDs) has enabled researchers to refine techniques to more effectively attract mosquitoes by using more precise light sources. For example, the Centers for Disease Control and Prevention (CDC) traps fitted with LEDs have greater light intensity with considerably lower energy requirement than the same traps in which incandescent bulbs are used, as is the normal practice (Burkett et al. 1998).

Although evaluations of trapping technology involving insect wavelength preferences and resting behavior have been studied extensively, the combination of the two has not. Few publications exist describing the attractiveness of LEDs to different mosquito species. Additionally, mosquito abundance in resting boxes when combined with a light source has not been published. Therefore, the objectives of this study were to determine wavelength preference of adult mosquitoes using LEDs, and to evaluate the attractiveness of resting boxes fitted internally with LEDs.

\section{MATERIALS AND METHODS}

All field trials were conducted at the University of Florida Horse Teaching Unit (HTU) and the Prairie Oaks subdivision (PO) near Gainesville, FL. Both locations were similar environments previously shown to have productive mosquito developmental sites (Butler, personal communication; Holton 2007). Both locations are adjacent to the Payne's Prairie State Preserve, and are surrounded by a mix of hardwood and pine forest with minimal undergrowth. The LEDs (Digi-Key Corporation, Thief River Falls, MN) used in these studies (part number, wavelength, and millicandela [mcd] rating, as described in Hoel [2005]), were blue (P466-ND, $470 \mathrm{~nm}, 650 \mathrm{mcd})$, green (67-1755-ND, $502 \mathrm{~nm}, 1,500 \mathrm{mcd})$, red (67-1611-ND, $660 \mathrm{~nm}$, $1,800 \mathrm{mcd}$ ), and infrared (IR) (LN77L-ND, 860 $\mathrm{nm})$. All LEDs consisted of a round lens and were $8.6 \mathrm{~mm}$ long by $5.0 \mathrm{~mm}$ in diam; viewing angles were $30^{\circ}$ except for IR $\left(20^{\circ}\right)$. A 180 -ohm resistor that was soldered to all LEDs restricted current flow to prevent mechanical failure.

Diode-equipped sticky card (DESC) studies were conducted using $20 \times 20 \mathrm{~cm}$ wooden boxes with 4 sides and an open top and bottom constructed from exterior-grade plywood. Each of the 4 outside surfaces was painted with flat black paint (Valspar, Wheeling, IL). A $13 \times 13$ cm black sticky card (EPA no. 057296-WI-001, Atlantic Paste \& Glue Corporation, Brooklyn, NY) was affixed to the exterior of each wall with 1 LED centered per vertical side. Black cards were selected to reduce variability of reflected light from LEDs. A hole drilled into the center of each sticky card and the box allowed for insertion of an LED from the inside of the DESC boxes so LEDs protruded outward through glue boards.

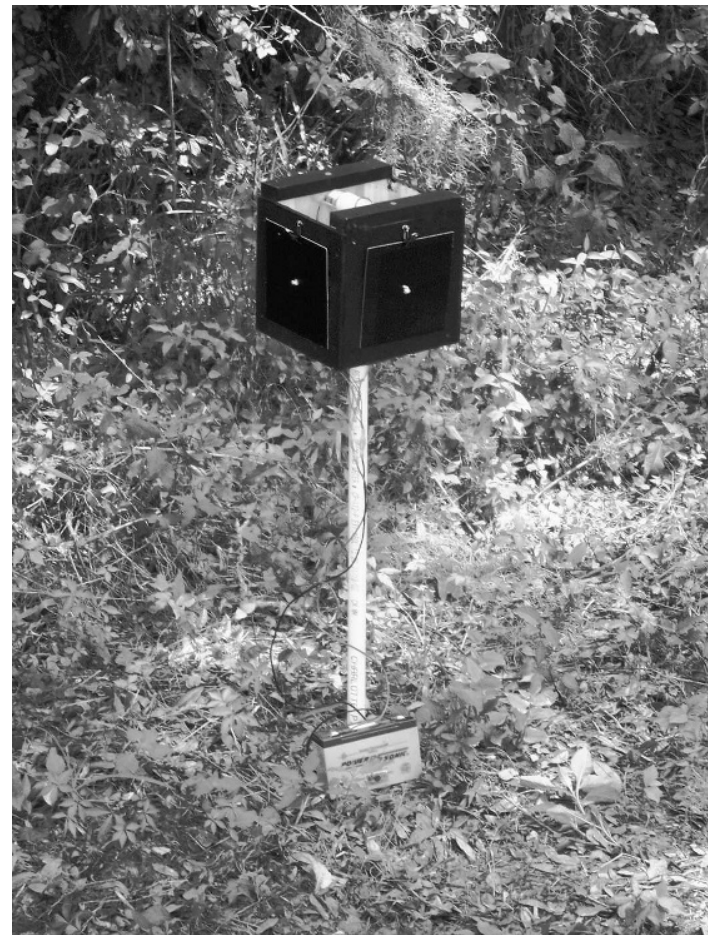

Fig. 1. Four sided, light-emitting diode-equipped sticky card box. One $13 \times 13 \mathrm{~cm}$ sticky card and one diode were affixed to each exterior wall of box.

Boxes were positioned $90 \mathrm{~cm}$ above ground (Fig. 1). Every $24 \mathrm{~h}$ the outward-facing sides of each DESC box were fitted with a randomly selected LED and a new sticky card, resulting in 32 light exposures per day ( 8 boxes $\times 4$ sides).

Diode-equipped resting boxes (DERB) with 4 sides, a back wall, and an open front were constructed using the specifications of a standard $30-\mathrm{cm}^{3}$ resting box, as described by Crans (1995) using exterior-grade plywood (Fig. 2a). Box exteriors were painted with flat black, and interiors were painted barn red (Valspar, Wheeling, IL) (Fig. 2b). A hole drilled through the back center wall allowed for the insertion of an LED. For each DERB trial, 4 sites contained 5 treatments, 1 of 4 LED colors (described previously) and an unlit control, resulting in a total of 5 resting boxes per site, 20 resting boxes per location (HTU and PO). Placement of resting boxes within a site was randomized at the start of the trial, and treatments (LED color) were randomized daily wherein LEDs were moved from box to box. Boxes were staged in a slightly offset line so that boxes in front did not disrupt the passage of the LED emission from those to the rear. All boxes were out of direct sunlight, and approximately $4 \mathrm{~m}$ apart, with the open sides facing west.

Three $\mathrm{CO}_{2}$-baited CDC light traps (model 512; John W. Hock Company, Gainesville, FL) with 


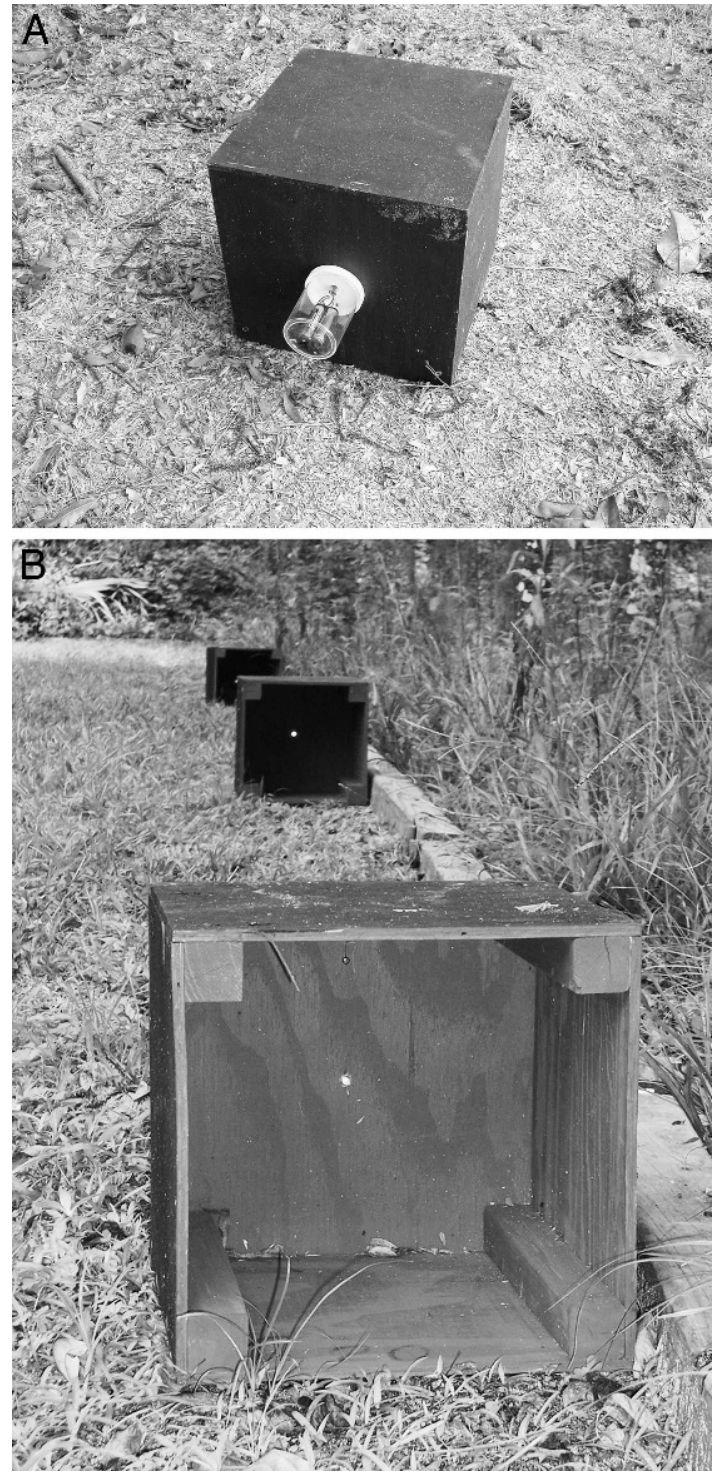

Fig. 2. Resting boxes. (A) Rear view of resting box showing protective diode housing. (B) Resting boxes were painted interiorly barn red and the exterior was black.

the incandescent bulb removed were operated simultaneously with the DESC and DERB trials and were used to provide a measure of background mosquito populations at each trial location. One CDC trap was placed at the HTU location and 2 were placed at the PO location. All traps were set $120 \mathrm{~cm}$ above ground using a shepherd's hook. Carbon dioxide was provided from a 9-kg compressed gas cylinder at a flow rate of $250 \mathrm{ml} / \mathrm{min}$ using a 5-psi single-stage regulator equipped with an inline microregulator (no. 007) and an inline filter (Clarke Mosquito Control, Roselle, IL). Flow rates were confirmed using a Gilmont Accucal ${ }^{\varpi}$ flowmeter (Gilmont Instrument Company, Barrington, IL).

Power to DESC LEDs and CDC traps were provided by $6 \mathrm{v}, 12$ ampere-hour (A-h) rechargeable gel cell batteries, which were changed every 24-48 h. Resting-box LEDs were powered by 4 rechargeable AA batteries, which were changed every 5 days. Temperature and humidity conditions were obtained from the Gainesville Regional Airport weather station through the online NOAA database (NOAA 2008).

Resting-box and sticky-card trials at both locations occurred in 20 trap-night clusters between July and September 2006, and between May and September 2007 for a total of between 120 and 157 trap nights, depending upon location and trial type (DESC or DERB). Twenty-four hours after deployment (1 trap night), sticky cards and CDC collection nets were removed and mosquitoes were aspirated from boxes. Treatments were rerandomized and traps reset. Mosquitoes collected in traps were brought back to the laboratory where they were counted by species and sex using the dichotomous keys of Darsie and Morris (2003).

Mosquito preference for LED wavelengths was evaluated using a multi-factorial ANOVA (SAS Institute 2001). For analysis, all data were normalized using the SQRT $(n+1)$ transformation; however, actual values are provided in text and tables. The model included the fixed effects of location, site, and LED treatment; the interaction term, location $\times$ LED treatment and the random effect trial. In instances where either the interaction term or the trial effect was significant, the data were analyzed separately by location or trial. Tukey's standardized test $(\alpha=$ 0.05 ) was used to separate treatment means.

\section{RESULTS}

\section{Diode-equipped sticky card boxes}

In the DESC trial 452 mosquitoes, including 15 mosquito species from 7 genera, were captured from both locations (Table 1). Significantly more female Aedes infirmatus Dyar and $\mathrm{Knab}\left(\mathrm{F}_{3}, 2,864\right.$ $=3.49 ; \quad P=0.0150)$, Aedes vexans Meigen $\left(\mathrm{F}_{3,2,544}=4.00 ; P=0.0074\right)$ and $C x$. nigripalpus Theobald $\left(\mathrm{F}_{3,2,544}=4.66 ; P=0.0030\right)$ were captured on DESCs fitted with blue diodes than on those with red or IR diodes (Table 2). Numerically, DESCs affixed with IR diodes caught the fewest female Ae. infirmatus, Ae. vexans, and $C x$. nigripalpus.

Coquillettidia perturbans males were recovered in significantly higher numbers on DESCs containing green diodes on than those with the blue or IR diodes $\left(\mathrm{F}_{3,2,226}=3.86 ; P=0.0091\right)$. Significantly more $C q$. perturbans female mosquitoes were captured on DESCs with green diodes 
Table 1. Relative total mosquito collection abundance from Centers for Disease Control and Prevention (CDC), diode-equipped sticky card, and resting-box trapping systems at 2 locations near Gainesville, FL.

\begin{tabular}{|c|c|c|c|}
\hline \multirow[b]{2}{*}{ Mosquito species } & \multicolumn{3}{|c|}{ Trap type ${ }^{1}$} \\
\hline & $\mathrm{CDC}^{2}$ & $\mathrm{DESC}^{3}$ & $\mathrm{RB}^{4}$ \\
\hline Aedes albopictus o & 0 & 1 & 0 \\
\hline Aedes albopictus 우 & 174 & 0 & 0 \\
\hline Aedes canadensis 우 & 6 & 0 & 0 \\
\hline Aedes fulvus pallens & 18 & 0 & 0 \\
\hline Aedes infirmatus o & 0 & 1 & 0 \\
\hline Aedes infirmatus $\bigcirc$ & 6,835 & 16 & 1 \\
\hline Aedes sollicitans $\bigcirc_{+}^{+}$ & 7,330 & 0 & 0 \\
\hline Aedes taeniorhynchus 우 & 18 & 0 & 0 \\
\hline Aedes triseriatus o & 0 & 1 & 0 \\
\hline Aedes triseriatus $\bigcirc$ & 96 & 11 & 1 \\
\hline Aedes vexans o & 0 & 4 & 0 \\
\hline Aedes vexans ㅇ & 10,577 & 22 & 0 \\
\hline Anopheles crucians o & 0 & 1 & 15 \\
\hline An. crucians $\bigcirc$ & 6,663 & 2 & 8 \\
\hline An. quadrimaculatus or & 0 & 1 & 82 \\
\hline An. quadrimaculatus $\bigcirc$ & 269 & 1 & 90 \\
\hline Coquillettidia perturbans ơ & 0 & 52 & 218 \\
\hline Cq. perturbans $\bigcirc$ & 63,833 & 80 & 109 \\
\hline Culex erraticus or $^{\prime}$ & 0 & 4 & 3,455 \\
\hline Cx. erraticus ㅇ & 19,773 & 21 & 2,985 \\
\hline$C x$. nigripalpus o $^{+}$ & 0 & 13 & 6 \\
\hline Cx. nigripalpus $\bigcirc$ & 52,885 & 23 & 22 \\
\hline Cx. quinquefasciatus ㅇ & 30 & 0 & 0 \\
\hline$C x$. salinarius $\mathrm{o}^{+}$ & 0 & 9 & 27 \\
\hline Cx. salinarius $\bigcirc$ & 4,168 & 8 & 13 \\
\hline Cx. territans $\mathrm{O}^{+}$ & 0 & 4 & 21 \\
\hline Cx. territans $\bigcirc$ & 0 & 3 & 38 \\
\hline Mansonia titillans or & 0 & 9 & 14 \\
\hline Ma. titillans $\bigcirc$ & 20,720 & 69 & 17 \\
\hline Psorophora ciliata 우 & 32 & 0 & 0 \\
\hline Psorophora columbiae ㅇ & 1,485 & 3 & 0 \\
\hline Psorophora ferox & 412 & 0 & 0 \\
\hline Uranotaenia lowii ơ & 64 & 37 & 1 \\
\hline Ur. lowii 우 & 0 & 6 & 23 \\
\hline Ur. sapphirina $\mathrm{o}^{\prime}$ & 704 & 50 & 4 \\
\hline Ur. sapphirina $ᄋ$ & 1,485 & 3 & 0 \\
\hline
\end{tabular}

${ }^{1} \mathrm{CDC}=$ Modified CDC light-trap; DESC $=$ diode-equipped sticky-card box; RB $=$ resting box.

${ }^{2}$ Trapping occurred simultaneously with DESC and RB trials, 380 trap nights.

${ }^{3}$ Trapping occurred from 16 August to 27 September 2006 and from 5 May to 13 September 2007, 260 trap nights.

${ }^{4}$ Trapping occurred from 21 July to 14 August 2006, and from 5 May to 26 September 2007, 448 trap nights.

than on DESCs fitted with red or IR diodes $\left(\mathrm{F}_{3,2,864}=4.66 ; P=0.0003\right)$ (Table 2). Mansonia titillans females were only captured at the HTU location in 2006. These mosquitoes preferred DESCs fitted with either blue or green LEDs over those with red or IR LEDs $\left(\mathrm{F}_{3}, 313=6.18 ; P=\right.$ 0.0004) (Table 2). Trap comparisons for all other species were not significant.

Approximately 91,766 female mosquitoes were captured using modified CDC traps over 360 trap nights. Overall, 21 species from 7 genera were captured (Table 1).

\section{Resting boxes}

A total of 7,157 adult mosquitoes, including 12 species from 6 genera, were recovered from resting boxes (Table 1). Although no significant differences were observed, $23 \%$ and $22 \%$ of all mosquitoes were recovered in IR and no-light DERBs, respectively. The fewest mosquitoes $(16.7 \%)$ were recovered in blue DERBs. Significantly more Anopheles quadrimaculatus females were aspirated from resting boxes fitted with red LEDs than from all other treatments $\left(F_{4}, 6,315=\right.$ 2.47; $P=0.0429$ ) (Table 3).

The year effect was significant for $C x$. erraticus males and females $\left(\mathrm{F}_{4,1,126}=2.40 ; P=0.0476\right)$. During 2006, no preferences were observed among diode treatments for either sex of this species. However, in 2007, significantly more $C x$. erraticus females were aspirated from resting boxes fitted with blue, green, and red LEDs, and from no-light boxes compared with boxes containing IR LEDs $\left(\mathrm{F}_{4,5,577}=8.41 ; P<0.0001\right)$ (Table 3). 
Table 2. Mean (SE) number of mosquitoes per trap night attracted to light-emitting diode wavelengths affixed to sticky cards positioned externally on wooden boxes during 24-h trapping intervals at 2 locations near Gainesville, FL.

\begin{tabular}{|c|c|c|c|c|c|}
\hline \multirow[b]{2}{*}{ Species } & \multirow[b]{2}{*}{$n^{2}$} & \multicolumn{4}{|c|}{ Mean $(\mathrm{SE})^{1}$} \\
\hline & & Blue $^{3}$ & Green $^{3}$ & $\operatorname{Red}^{3}$ & Infrared $^{3}$ \\
\hline Aedes infirmatus ? & 720 & $0.014(0.004) \mathrm{a}$ & $0.004(0.002) \mathrm{ab}$ & $0.003(0.002) b$ & $0.001(0.001) \mathrm{b}$ \\
\hline Aedes vexans & 640 & $0.019(0.006) \mathrm{a}$ & $0.013(0.004) \mathrm{ab}$ & $0.002(0.002) b$ & $<0.001(<0.001) b$ \\
\hline Coquillettidia perturbans $\mathrm{O}^{\prime}$ & 560 & $0.014(0.006) \mathrm{b}$ & $0.043(0.010) \mathrm{a}$ & $0.011(0.006) \mathrm{ab}$ & $0.016(0.005) \mathrm{b}$ \\
\hline Coquillettidia perturbans $\bigcirc$ & 720 & $0.031(0.007) \mathrm{ab}$ & $0.049(0.009) \mathrm{a}$ & $0.024(0.007) b$ & $0.008(0.003) b$ \\
\hline Culex erraticus 우 & 320 & $0.034(0.012) \mathrm{a}$ & $0.016(0.007) \mathrm{ab}$ & $0.013(0.006) \mathrm{ab}$ & $0.003(0.003) \mathrm{b}$ \\
\hline Culex nigripalpus ㅇ & 640 & $0.019(0.007) \mathrm{a}$ & $0.016(0.005) \mathrm{ab}$ & $0.002(0.002) \mathrm{b}$ & $<0.001(<0.001) \mathrm{b}$ \\
\hline Mansonia titillans 2006 ㅇ & 80 & $0.313(0.068) \mathrm{a}$ & $0.363(0.110) \mathrm{a}$ & $0.100(0.038) b$ & $0.050(0.025) \mathrm{b}$ \\
\hline
\end{tabular}

${ }^{1}$ Means within rows followed by the same letter were not significantly different $(P<0.05$, Tukey's standardized test [SAS Institute 2001]).

${ }^{2} n=$ number of trap nights where total mosquito species capture was $\geq 1$ mosquito per 20 trap nights

${ }^{3}$ Blue diode $=470 \mathrm{~nm}$, green diode $=502 \mathrm{~nm}$, red diode $=660 \mathrm{~nm}$, infrared diode $=860 \mathrm{~nm}$.

Notable differences between treatment responses were observed among the 177 blood-fed mosquitoes recovered from resting boxes. Unlit resting boxes (control) accounted for the greatest number of blood-fed mosquitoes recovered, followed by resting boxes fitted with green, IR, and blue LEDs (Table 4). No blood-fed mosquitoes were recovered from resting boxes fitted with red LEDs. Among mosquito species, $74 \%$ of all blood-fed mosquitoes recovered were $C x$. erraticus.

Approximately 100,653 female mosquitoes were trapped in the $3 \mathrm{CDC}$ traps over 448 trap nights. Overall, 21 species from 8 genera were captured (Table 1). CDC traps were functional for $>91 \%$ of trap nights.

\section{DISCUSSION}

Overall, capture of mosquitoes on DESCs was greatest with blue LEDs, followed by green, red, and IR LEDs. Similarly, previous studies have shown host-seeking mosquito wavelength preference to be in the blue-green range $(400-600 \mathrm{~nm})$, with diminishing attraction as wavelengths in- crease in length ( $>600 \mathrm{~nm}$ ) (Ali et al. 1989, Burkett et al. 1998).

Our findings agree with Bargren and Nibley's (1956) observations, where considerably more Ae. vexans were captured on DESCs fitted with blue diode treatments. However, we observed no significant differences in wavelength preference for Culex salinarius. In contrast to Burkett et al. (1998), considerably more Cx. nigripalpus were captured on DESCs fitted with blue diodes than on those with red diodes. These results suggest a spectral sensitivity for $C x$. nigripalpus females at the higher end of the blue spectrum $(>450 \mathrm{~nm})$, with decreasing sensitivity for wavelengths from $450 \mathrm{~nm}$ toward the lower end of the red spectrum $(<640 \mathrm{~nm})$.

Browne and Bennett (1981) and Ali et al. (1989) determined that shorter, blue-green wavelengths $(400-600 \mathrm{~nm}$ and $430-550 \mathrm{~nm}$, respectively) attracted significantly more $C q$. perturbans than did longer wavelengths. These results were comparable to our observations where significantly more $C q$. perturbans were captured on DESCs affixed with lower-spectrum green diodes $(502 \mathrm{~nm})$, and fewer were captured on DESCs

Table 3. Mean (SE) mosquitoes/trap night attracted to 4 light-emitting diode wavelengths placed in resting boxes near Gainesville, FL.

\begin{tabular}{|c|c|c|c|c|c|c|}
\hline \multirow[b]{2}{*}{ Species } & \multirow[b]{2}{*}{$n^{3}$} & \multicolumn{5}{|c|}{ Mean $(\mathrm{SE})^{1,2}$} \\
\hline & & Blue & Green & Red & Infrared & No Light \\
\hline \multicolumn{7}{|l|}{ Anopheles quadrimaculatus } \\
\hline 2006-2007 \& & 1,268 & $0.004(0.003) b$ & $0.013(0.007) b$ & $0.032(0.013) \mathrm{a}$ & $0.007(0.005) b$ & $0.015(0.005) b$ \\
\hline Culex erraticus 2006 o" & 288 & $2.154(0.333)$ & $2.452(0.396)$ & $3.009(0.453)$ & $3.868(0.617)$ & $3.154(0.501)$ \\
\hline Culex erraticus 2007 or & 1,120 & $0.022(0.005)$ & $0.028(0.006)$ & $0.024(0.005)$ & $0.021(0.005)$ & $0.032(0.007)$ \\
\hline Culex erraticus 2006 우 & 148 & $2.851(0.558)$ & $2.980(0.546)$ & $3.223(0.616)$ & $3.967(0.710)$ & $3.932(0.740)$ \\
\hline Culex erraticus 2007 ㅇ & 1,120 & $0.113(0.012) \mathrm{a}$ & $0.087(0.011) \mathrm{a}$ & $0.083(0.010) \mathrm{a}$ & $0.038(0.007) \mathrm{b}$ & $0.104(0.012) \mathrm{a}$ \\
\hline
\end{tabular}

\footnotetext{
${ }^{1}$ Means within rows followed by the same letter were not significantly different $(P<0.05$, Tukey's standardized test [SAS Institute 2001]). Means in rows without means separation letters were not significantly different.

${ }^{2}$ Blue diode $=470 \mathrm{~nm}$, green diode $=502 \mathrm{~nm}$, infrared diode $=860 \mathrm{~nm}$, red diode $=660 \mathrm{~nm}$, and no light indicates no diode treatment.

${ }^{3} n=$ number of trap nights in which total mosquito species captured was $\geq 1$ per 20 trap nights. Trapping occurred from July 2006 to September 2007.
} 
Table 4. Total blood-fed mosquitoes attracted to light-emitting diodes of 4 different wavelengths placed in resting boxes compared with resting boxes without lights near Gainesville, FL.

\begin{tabular}{lcccrrr}
\hline \hline & \multicolumn{5}{c}{ Diode treatment $^{1}$} \\
\cline { 2 - 5 } \multicolumn{1}{c}{ Mosquito species } & Blue & Green & Red & Infrared & No light & Total \\
\hline Anopheles crucians & 0 & 3 & 0 & 2 & 2 \\
Anopheles quadrimaculatus & 0 & 0 & 0 & 2 & 0 & 7 \\
Coquillettidia perturbans & 7 & 9 & 0 & 5 & 28 \\
Culex erraticus & 26 & 33 & 0 & 30 & 43 \\
Culex salinarius & 1 & 4 & 0 & 0 & 1 \\
Culex territans & 1 & 1 & 0 & 1 & 7 \\
Total & 35 & 50 & 40 & 54 & 179
\end{tabular}

${ }^{1}$ Blue diode $=470 \mathrm{~nm}$, green diode $=502 \mathrm{~nm}$, red diode $=660 \mathrm{~nm}$, infrared diode $=860 \mathrm{~nm}$, and no light indicates no diode treatment.

fitted with higher-spectrum IR (860-nm) diodes. Through the use of more scientifically accurate LEDs, our results demonstrated a stronger preference of $C q$. perturbans for green wavelengths (502 $\mathrm{nm})$ than for blue $(470 \mathrm{~nm})$, suggesting wavelength attraction of this species was nearer to the green range of the blue-green spectrum $(>500 \mathrm{~nm})$.

Ali et al. (1989) reported higher capture rates for $C x$. erraticus when using blue-colored bulbs (430-490 nm) compared with red-colored bulbs $(620-720 \mathrm{~nm})$ of comparable intensity. Similarly, we captured significantly more $C x$. erraticus females on DESCs affixed with blue diodes than on DESCs fitted with IR diodes, but observed no significant preferences between blue, green, or red diodes. However, we recovered more male $C X$. erraticus (26\%) from resting boxes fitted with IR LEDs, and more females (23\%) from unlit boxes. Therefore, wavelength preferences for host-seeking $C x$. erraticus may range in the lower bands of the spectrum $(<470 \mathrm{~nm})$, whereas resting $C x$. erraticus may be averse to these wavelength bands.

No blood-fed An. quadrimaculatus were recovered from DERBs fitted with red LEDs, suggesting a physiological stage-dependant behavior. Therefore, the addition of $>660-\mathrm{nm}$ LEDs to resting boxes may enhance efficacy of sampling host-seeking An. quadrimaculatus populations, whereas their inclusion may repel blood-fed $A n$. quadrimaculatus.

Although not significant, the trends observed in DERB trials suggest that resting mosquitoes may choose the higher wavelengths of light and dark boxes over the lower wavelengths of light that attract host-seeking mosquito species. Lower wavelengths are preferred for phototactic, hostseeking mosquito species trapped at night, such as Cx. erraticus, Cx. nigripalpus, and Ps. columbiae (Bargren and Nibley 1956, Ali et al. 1989, Burkett et al. 1998, Burkett and Butler 2005). These behavioral differences between host-seeking mosquitoes and those captured in resting boxes may be the product of variation in wavelength attraction between the physiological stages and deserves further attention. Additionally, our use of narrow wavelengths may have excluded mosquitoes preferring longer or shorter wavelength bands than those selected.

Although no blood-fed mosquitoes were captured using DESCs, 179 blood-fed mosquitoes were recovered from resting boxes. Culex erraticus was the most common blood-fed mosquito recovered, accounting for $74 \%$ of all blood-fed mosquitoes captured. This high recovery rate is likely because of the elevated presence of $C x$. erraticus among all mosquito species recovered from resting boxes throughout this study. Among treatments, $43 C x$. erraticus were recovered from resting boxes fitted with IR LEDs. Although resting boxes fitted with IR LEDs recovered the highest number of blood-fed mosquitoes, it is important to note that no blood-fed mosquitoes were recovered from resting boxes fitted with red LEDs. Our observations may suggest a variation in wavelength preferences among host-seeking and blood-fed mosquitoes. These findings provide important information that warrants further investigation into behavioral phototaxis differences among physiological stages of mosquitoes.

The results of our study suggest that, in the absence of alternative host stimuli, wavelengths in the lower green $(502 \mathrm{~nm})$ spectral range would be optimal for targeting a broad range of mosquito species. Additionally, the use of LEDs as opposed to wavelength filters or colored bulbs provides a more precise and energy efficient delivery system for spectrally sensitive insects.

Although the $\mathrm{CO}_{2}$-baited CDC trap captured considerably more host-seeking mosquitoes, the DERB and DESC provide an alternative trapping system. Given their accuracy in specific wavelength achievement, small size, and minimal power usage, LEDs can be used as light sources for various trap designs where access and equipment to target sites are limited. Their demonstrated effectiveness for attracting mosquitoes without the aid of supplemental host attractants further eliminates the need for and costs of heavy tanks $\left(\mathrm{CO}_{2}\right)$ or volatile chemicals 
(lactic acid, octenol). The durability of the LEDbased equipment also reduces time-consuming maintenance.

\section{ACKNOWLEDGMENTS}

The authors thank J. Butler, S. TenBroeck, J. Calahan, and the residents of the Prairie Oaks Subdivision for allowing access to their properties. The authors would also like to acknowledge J. Pitzer and P. Obenauer for their involvement and assistance. This study was supported by the University of Florida Agricultural Experiment Station federal formula funds, Project No. FLA04598, received from Cooperative State Research, Education, and Extension Service, US Department of Agriculture. Thank you to J. Cilek for reviewing a draft of this publication.

\section{REFERENCES CITED}

Ali A, Nayar JK, Knight JW, Stanley BH. 1989. Attraction of Florida mosquitoes (Diptera: Culicidae) to artificial light in the field. Proc Calif Mosq Vector Control Assoc 57:82-88.

Allan SA, Stoffolano JG. 1986. Effects of hue and intensity on visual attraction of adult Tabanus nigrovittatus (Diptera: Tabanidae). J Med Entomol 23:83-91.

Bargren WC, Nibley C. 1956. Comparative attractiveness of colored lights of equal intensity to specific species of mosquitoes. 3rd Area Med Lab, Fort McPherson, GA.

Barr AR, Smith TA, Boreham M, White KE. 1963. Evaluation of some factors affecting the efficiency of light traps on collecting mosquitoes. J Econ Entomol 56:123-127.

Bidlingmayer WL. 1967. A comparison of trapping methods for adult mosquitoes: species response and environmental influence. $J$ Med Entomol 4:200-220.

Bracken GK, Hanec W, Thorsteinson AJ. 1962. The orientation of horseflies and deerflies (Tabanidae: Diptera). II. The role of some visual factors in the attractiveness of decoy silhouettes. Can $J$ Zool 40:685-695.

Bradbury WC, Bennett GF. 1974. Behavior of adult Simuliidae (Diptera). I. Response to color and shape. Can J Zool 52:251-259.

Bradley GH. 1943. Determination of densities of Anopheles quadrimaculatus on the wing. Proc Annu Meet N J Mosq Extermination Assoc 30:22-27.

Brett GA. 1938. On the relative attractiveness to Aedes aegypti of certain coloured cloths. Trans $R$ Soc Trop Med Hyg 32:113-124.
Browne SM, Bennett GF. 1981. Response of mosquitoes (Diptera: Culicidae) to visual stimuli. $\mathrm{J} \mathrm{Med}$ Entomol 18:505-521.

Burkett DA, Butler JF. 2005. Laboratory evaluation of colored light as an attractant for female Aedes aegypti, Aedes albopictus, Anopheles quadrimaculatus and Culex nigripalpus. Fla Entomol 88:383-389.

Burkett DA, Butler JF, Kline DL. 1998. Field evaluation of colored light-emitting diodes as attractants for woodland mosquitoes and other Diptera in north central Florida. J Amer Mosq Control Assoc 14:186-195.

Crans WJ. 1995. Resting boxes as mosquito surveillance tools. Proc New Jersey Mosq Control Assn 82:53-57.

Darsie RF, Morris CD. 2003. Keys to the adult females and fourth instar larvae of the mosquitoes of Florida (Diptera, Culicidae). Volume 1. De Leon Springs, FL: E. O. Painter Printing Co.

Fox I. 1958. The mosquitoes of the international airport, Isla Verde, Puerto Rico, as shown by light traps. Mosq News 18:117-124.

Goodwin MN. 1942. Studies on artificial resting places of Anopheles quadrimaculatus Say. J Natl Malaria Soc 1:93-99.

Hayes RO, Bellamy RE, Reeves WC, Willis MJ. 1958. Comparison of four sampling methods for measurement of Culex tarsalis adult populations. Mosq News 20:174-178.

Headlee TJ. 1937. Some facts underlying the attraction of mosquitoes to sources of radiant energy. $J$ Econ Entomol 30:309-312.

Hoel D. 2005. Response of Aedes albopictus (Diptera: Culicidae) to traps, attractants, and adulticides in north central Florida. [Ph.D. dissertation]. University of Florida, Gainesville, FL.

Holton AC. 2007. Evaluation of different commercial lures and horse odors as an attractant and their abilities to increase mosquito trap numbers at the University of Florida Horse Teaching Unit. [M.S. thesis]. University of Florida, Gainesville, FL.

Huffaker CB, Back RC. 1943. A study of methods of sampling mosquito populations. J Econ Entomol 36:561-569.

Loomis EC, Sherman EJ. 1959. Comparison of artificial shelters and light traps for measurement of Culex tarsalis and Anopheles freeborni populations. Mosq News 19:232-237.

NOAA [National Oceanic and Atmospheric Administration]. 2008. Gainesville weather information 2006 2007. [Internet]. Gainesville, FL: NOAA. [accessed September 3, 2007]. Available from: http://forecast. weather.gov/MapClick.php?CityName $=$ Gainesville $\&$ state $=$ FL\&site $=$ JAX\&textField $1=29.6742 \&$ textField $2=$ $-82.3363 \& \mathrm{e}=0$.

SAS Institute. 2001. SAS/STAT user's manual, Version 8.2. Cary, NC: SAS Institute.

Service MW. 1993. Mosquito ecology: field sampling methods. 2nd ed. London: Elsevier Applied Science. 